\title{
Periventricular Heterotopia: New Insights into Ehlers-Danlos Syndrome
}

\author{
Volney L. Sheen, MD, PhD and Christopher A. Walsh, MD, PhD
}

\begin{abstract}
Nature often employs similar mechanisms to complete similar tasks, thus the evolution of homologous proteins across various organ systems to perform similar but slightly different functions. In this respect, disorders attributed to specific genetic mutations, while initially thought to be restricted in function and purpose, may provide broad insight into general cellular and molecular mechanisms of development and maintenance. One such example can be seen in the brain malformation, periventricular heterotopia $(\mathrm{PH})$, which is characterized by very specific nodules of neurons that line the lateral ventricles beneath the cerebral cortex. $\mathrm{PH}$ is seen as a disorder of neuronal migration and can be caused by mutations in filamin A (FLNA), which encodes an actin-binding protein that regulates the cytoskeleton and cell motility. Recent advances in our understanding of the genetic causes of PH suggest that mutations in this gene, however, are also associated with the connective tissue disorder, Ehlers-Danlos syndrome (EDS), in which affected individuals present with joint and skin hyperextensibility and vascular problems including aortic dissection, excessive bleeding and bruisability. While much still remains unknown regarding the mechanistic role of FLNA in giving rise to $\mathrm{PH}$ and EDS, a common cellular and molecular basis likely gives rise to these two seemingly unrelated clinical disorders.
\end{abstract}

Keywords: Central nervous system/pathology; Collagen; Connective tissue; Cortical development; Ehlers-Danlos syndrome; Filamin A; Inherited disorders, CNS; Periventricular heterotopia

G enetics of Periventricular Heterotopia and Ehlers-Danlos Syndrome

Periventricular heterotopia $(\mathrm{PH})$ has been interpreted as a disorder in neuronal migration where newly born neurons fail to migrate from their birthplace along the lining of the lateral ventricles of the brain, thereby giving rise to the characteristic ectopically placed neuronal nodules (figure 1). Mutations in two genes have been identified as the genetic cause of $\mathrm{PH}$. The more common X-linked dominant form of $\mathrm{PH}$ is due to mutations in the filamin A (FLNA) gene. ${ }^{1,2}$ At least $80 \%$ of all familial cases of $\mathrm{PH}$ are due to a FLNA mutation with some $20 \%$ of sporadic cases attributable to this gene. ${ }^{3}$ A much more rare autosomal recessive form of $\mathrm{PH}$ with microcephaly results from mutations in the ARFGEF2 gene which encodes the brefeldin-inhibited guanine exchange factor 2 (BIG2) protein. ${ }^{4}$ Filamin A interacts with the actin cytoskeleton and thereby regulates various aspects of cell shape, motility and function. ${ }^{5}$ BIG2 regulates vesicle trafficking from the trans-Golgi apparatus to the cell surface

Reprint Requests: Christopher A. Walsh, MD, PhD, Division of Neurogenetics and Howard Hughes Medical Institute, Department of Neurology, Beth Israel Deaconess Medical Center, NRB 2, 77 Avenue Louis Pasteur, Boston, MA 02।I5, Tel: 617-667-08।3, Fax: 617-667-08। 5

E-mail: cwalsh@bidmc.harvard.edu in various tissues of the body. Potentially, the secreted or surface proteins transported through BIG2-dependent vesicles may interact with filamin A near the cell surface and disruption of these as proteins could give rise to $\mathrm{PH}$ by impairing neuronal migration.

Ehlers-Danlos syndrome (EDS) describes a heterogeneous group of disorders, which mainly affect the skin, joints and vasculature, but uniformly involve defects in collagen. Diagnosis of EDS and sub-classification into one of the six major subtypes of EDS is based on major (skin hyperextensibility, joint hypermobility, skin fragility and scarring, vascular fragility, kyphoscoliosis and scleral involvement) and minor diagnostic criteria. ${ }^{6}$ Mutations in different collagens and collagen-modifying enzymes have been recognized for all sub-types of EDS with the exception of type III hypermobility-type EDS. ${ }^{7}$ The collagens represent a large family of structurally related extracellular matrix proteins essential for development, cell attachment, platelet aggregation and for providing tensile strength to the

Received: July 2, 2005 Revised: September 7, 2005 Accepted: September 9, 2005

Grant Support: Grants from the National Institute of Neurological Disorders and Stroke (2R37 NS35I29 IPOINS40043), March of Dimes, and the McKnight Foundation (C.A.W.).V.L.S. is supported by grant IK08MH/NS63886-0I from the National Institute of Mental Health, Julian and Carol Cohen, and the Milton Fund.V.L.S. is a Charles A. Dana fellow and a Beckman Young Investigator. 


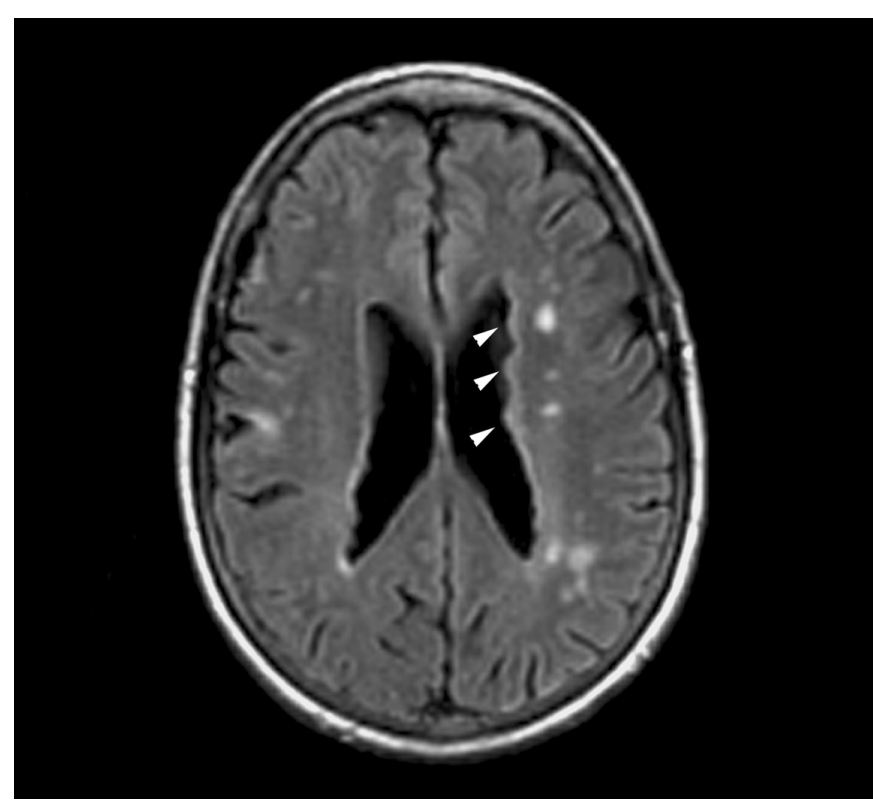

Figure 1. Radiographic phenotype of periventricular heterotopia. Axial T1-weighted magnetic resonance image of the brain demonstrates bilateral periventricular nodular heterotopia (white arrowheads) along the lateral ventricles. While not commonly appreciated, this particular patient also had small vessel ischemic changes at an early age, suggestive of some abnormality in the blood vessels.

connective tissues in bone, skin, ligaments and tendons, and blood vessels. ${ }^{8}$ Loss of the elasticity and strength of collagen in EDS presumably contributes to the structural failure in connective tissue of the various affected organ systems.

\section{Clinical Presentations Associated with PH and FLNA Mutations}

Recently, we have identified FLNA mutations in patients with $\mathrm{PH}$ who have independently been identified as having EDS. $^{2}$ While affected patients have nodular brain heterotopia, they also exhibit features consistent with EDS, including joint hypermobility, skin fragility and aortic dilation in early adulthood. The inheritance pattern in $\mathrm{PH}$ and EDS follows that expected of an X-linked dominant disorder, such as FLNA with affected females and presumptive hemizygous male lethality. Initial studies suggested linkage to chromosome Xq28, the FLNA locus. Of the nine sporadic cases of PH and EDS ( 8 females and 1 male), three FLNA mutations were identified (2762 del G single base pair deletion, $\mathrm{C} 116 \mathrm{G}$ resulting in an A39G change, 4147 del G single base pair deletion). Of the two families with $\mathrm{PH}$ and EDS, one pedigree was initially reported as having no exonic mutation, but filamin A protein could not be detected on Western blot analyses suggesting some disruption in this gene. ${ }^{2}$ Denaturing high performance liquid chromatography has subsequently detected a C3742T base pair change resulting in a premature stop Q1248X in this family (personal communications, Dr. Stephen Robertson). No clear correlation exists between the type of mutation and presentation of EDS which suggests that the clinical features of EDS may reflect some degree of variable penetrance. ${ }^{3}$ Moreover, it is not known whether individuals with EDS in the absence of PH may harbor FLNA mutations.

Many features of EDS can also be seen in affected individuals with PH but no formal diagnosis of a connective tissue disorder. Patients have been reported to have patent ductus arteriosus, bicuspid aortic valve, or aneurysmal dilatation of the sinus of Valsalva and/or thoracic aorta at young ages, but the true prevalence of these cardiac abnormalities are not yet known. ${ }^{1}$ Hemizygous males who lack a normal copy of the X-linked FLNA gene generally die prenatally from excessive bleeding. ${ }^{9}$ Congenital gut and genitourinary anomalies have also been reported in boys harboring FLNA mutations. ${ }^{1,10}$ Several recurrent missense mutations in the actin-binding and rod domains of the FLNA gene have likewise been implicated in malformations affecting craniofacial structures and the skeleton. ${ }^{11-13}$ These syndromes, however, are thought to arise from a gain-of-function mutation in this gene. Overall, the broad spectrum of abnormalities attributable to FLNA mutations mirrors the widespread abnormalities in the vasculature, gut and bone associated with connective tissue disorders.

Neurological symptoms (primarily seizures and dyslexia) are the most common presenting features associated with $\mathrm{PH}$ due to FLNA mutations. Approximately $90 \%$ of patients have focal epilepsy. ${ }^{14}$ Retrospective studies would suggest that the prognostic outcome of the epilepsy is dependent upon the electrographic and neuroradiological findings for the particular patient with $\mathrm{PH}$. When imaging demonstrates $\mathrm{PH}$ in the absence of other brain malformations, patients generally have normal intelligence with their seizures beginning in the second decade of life. The EEG often shows only focal abnormalities, and the seizures usually do not become frequent and generally disappear. When the $\mathrm{PH}$ is associated with other cortical or cerebral malformations, patients may have mental retardation, and the seizures generally begin during the first decade of life. The EEG often shows focal and bisynchronous abnormalities, and the epilepsy generally increases in frequency and may become refractory. ${ }^{15}$ Recent studies have also suggested a high incidence of dyslexia in the PH population. ${ }^{16}$ Since most patients with $\mathrm{PH}$ have normal intelligence, the dyslexia is not commonly recognized. Neurocognitive studies, however, suggest that some $80 \%$ of individuals with $\mathrm{PH}$ have deficits in reading, processing speed and executive function. The extent of this impairment is not correlated with the type of seizure medications or the severity of seizures, but is more severe when more widely distributed heterotopia is noted on imaging.

\section{Potential Pathogenic Mechanisms in PH and EDS}

The recent association between $\mathrm{PH}$ and EDS potentially broadens the current understanding of the molecular pathogenesis of EDS. EDS is typically viewed as a disorder of the extracellular matrix involving disruption in glycoproteins, such as collagen or proteoglycans such as 
Table 1. Widespread and overlapping features between Ehlers-Danlos syndrome and filamin related disorders.

\begin{tabular}{|c|c|c|c|}
\hline Types & Protein & Gene & Organ system \\
\hline \multicolumn{4}{|l|}{ Ehlers-Danlos Syndrome } \\
\hline Type I/II classic & Type $\mathrm{V}$ procollagen & COL5A1/COL5A2 & Skin hyperextensibility \\
\hline Type III hypermobility & Unknown & Unknown & Joint hypermobility \\
\hline Type IV vascular & Type III procollagen & COL3A1 & Blood vessel fragility \\
\hline Type VI kyphoscoliotic & Lysyl hydroxylase 1 & PLOD1 & $\begin{array}{l}\text { Muscular hypotonia } \\
\text { Kyphoscoliosis }\end{array}$ \\
\hline Type VIIA/B arthrochalasis & Type I procollagen & COL1A1/COL1A2 & Joint hypermobility \\
\hline Type VIIC dermatosparaxis & Procollagen-N-proteinase & ADAMTS-2 & Skin hyperextensibility \\
\hline \multicolumn{4}{|l|}{ Filamin Protein Syndromes } \\
\hline Periventricular heterotopia (300049) & Filamin A & FLNA & Brain heterotopia \\
\hline Otopalatodigital syndrome type I (311300) & Filamin A & FLNA & Bone anomalies \\
\hline Otopalatodigital syndrome type II (304120) & Filamin A & FLNA & Bone anomalies \\
\hline Frontometaphyseal dysplasia (305620) & Filamin A & FLNA & Bone anomalies \\
\hline Melnick-Needles syndrome (309350) & Filamin A & FLNA & Bone anomalies \\
\hline Ehlers-Danlos variant of periventricular heterotopia (300537) & Filamin A & FLNA & $\begin{array}{l}\text { Joint hypermobility } \\
\text { Skin hyperextensibility } \\
\text { Blood vessel fragility }\end{array}$ \\
\hline Spondylocarpotarsal syndrome (272460) & Filamin B & FLNB & $\begin{array}{l}\text { Bone anomalies } \\
\text { Joint hypermobility } \\
\text { Scoliosis }\end{array}$ \\
\hline Autosomal dominant Larsen syndrome (150250) & Filamin B & FLNB & $\begin{array}{l}\text { Bone anomalies } \\
\text { Joint hypermobility }\end{array}$ \\
\hline Type I atelosteogenesis (108720) & Filamin B & $F L N B$ & Bone anomalies \\
\hline Type III atelosteogenesis (108721) & Filamin B & FLNB & Bone anomalies \\
\hline Myofibrillar myopathy & Filamin C & FLNC & Muscle \\
\hline
\end{tabular}

elastin or other extracellular matrix proteins including tenascin-X. ${ }^{17}$ Cells attach to the extracellular matrix by means of transmembrane glycoproteins called integrins, whose intracellular portion binds to the actin filaments of the cytoskeleton. Moreover, filamin A has been shown to bind the $\beta$-integrin cell adhesion receptors, ${ }^{18}$ but does not alter the formation of these focal adhesion sites and does not alter the extracellular matrix assembly. ${ }^{19}$ Thus, the finding of $\mathrm{PH}$ and EDS due to FLNA mutations would suggest a novel intracellular cause of EDS. Perhaps FLNA mutations cause EDS by decreasing the strength of attachment of the cells to the extracellular matrix or by impaired regulation of the cytoskeleton through the filamin binding to integrin proteins. Reflecting back on the brain defect, PH may not represent a disorder of cell motility. Rather, impaired structural integrity of the neuroependyma may weaken the ventricular lining during neurogenesis and lead to $\mathrm{PH}$ formation, much in the same manner by which the aorta dilates and the skin becomes overly extended from increased stress in EDS.

A more direct relationship between filamin and collagen can be appreciated when examining the mechanisms involved in platelet aggregation in which mutations in the FLNA (EDS variant of $\mathrm{PH}$ ) and in COL3A1 (vascular type EDS) are both known to cause excessive bleeding, presumably from vascular fragility and platelet dysfunction. 5,8 When the integrity of the vascular wall is compromised, as in vascular EDS, platelets adhere to subendothelial collagens exposed at the sites of blood vessel injury via the glycoprotein (GP) Ib-V-IX complex and integrin $\alpha 2 \beta 1 .{ }^{8}$ This initial platelet entrapment requires the plasma protein von Willebrand factor, which simultaneously binds the GP and integrin complex and facilitates platelet tethering and rolling. More stable binding of collagen to the platelet collagen receptors (namely integrin $\alpha 2 \beta 1$ and GPVI) follows this initial interaction. In the vascular type of EDS, impaired collagen integrity disrupts this process. Likewise, filamin A binds both the integrin and the GPIb-IX complex, and studies suggest that the association of this receptor complex with the membrane skeleton, while not essential for platelet tethering or rolling under low shear conditions, is critical for maintaining platelet adhesion at high shear rates. ${ }^{20}$ Thus, the interactions between the extracellular collagen matrix, the platelet collagen receptors, filamin and the cytoskeleton collectively mediate platelet adhesion, activation and subsequent hemostasis.

Much in the same manner, whereby the widespread and overlapping distribution of different collagens contributes to 
the multi-organ system involvement in EDS, the broad distribution of filamin proteins reflects its widespread function and potential interactions with the extracellular matrix (see table 1). The filamin family of actin-binding proteins are composed of three highly homologous members: filamin A, filamin B and filamin C. Mutations in FLNA primarily involve abnormalities of the central nervous system, skeletal and vascular system.1,3 Mutations in the filamin B gene lead to skeletal and joint deformities. ${ }^{21}$ Mutations in the filamin $\mathrm{C}$ gene cause a myopathy. ${ }^{22}$

\section{Tests Available in the Diagnosis of PH}

In most cases, patients with $\mathrm{PH}$ have normal intelligence and no focal neurological findings on examination. Seizures are the most common presenting feature and the heterotopic nodules are incidentally observed following radiographic imaging.

Definitive diagnosis of $\mathrm{PH}$ is made through radiographic imaging. In X-linked PH due to FLNA mutations, magnetic resonance images uniformly demonstrate bilateral near-continuous nodular PH, typically in females. Findings of a thinned corpus callosum and mega cisterna magna are often associated with this disorder. ${ }^{1}$ There are no consistent radiographic differences between patients carrying different mutations. ${ }^{23} \mathrm{PH}$ and mega cisterna magna, while subtle, can also be appreciated by ultrasonography during the second trimester. ${ }^{24}$ Positron emission tomography and single photon emission computed tomography scans suggest the glucose metabolism and perfusion of the heterotopic gray matter are identical to the normal cerebral cortex. ${ }^{25}$ In the autosomal recessive form of $\mathrm{PH}$ due to $A R F G E F 2$ mutations, magnetic resonance images also demonstrate bilateral near-continuous nodular PH but have distinguishing features of microcephaly, mild ventriculomegaly and white matter changes. ${ }^{4}$

Definitive diagnosis of genetic causes of $\mathrm{PH}$ requires molecular testing for the genes, although this service is primarily performed on a research basis only.

\section{Treatment of PH}

No uniform guidelines exist for the management of complications from PH (namely seizures), although treatment generally follows standard guidelines involving focal epilepsies. In most cases, management through anti-convulsant medications is sufficient in controlling events. ${ }^{15}$ For intractable focal seizures requiring surgical resection, the best predictor of surgical outcome is the capacity to localize the focal epileptic generator, which may or may not include the heterotopia, through invasive recording by stereoencephalography. ${ }^{26}$ Resection of the epileptogenic zones from patients with unilateral rather than bilateral $\mathrm{PH}$ also faired better. ${ }^{27}$

\section{Conclusions}

The diagnosis of PH and an awareness of potential problems associated with this disorder, particularly the risk of vascular dissection and dyslexia, should prompt a more careful initial evaluation and routine followup. An argument can be made for imaging of large vessels of the body given the risk of aortic dilation and rupture before the age of 40 . Similarly, a battery of neuropsychological testing should be considered in instances where learning deficits are suspected.

\section{References}

1. Fox JW, Lamperti ED, Eksioglu YZ, Hong SE, Feng Y, Graham DA, Scheffer IE, Dobyns WB, Hirsch BA, Radtke RA, Berkovic SF, Huttenlocher PR, Walsh CA. Mutations in filamin 1 prevent migration of cerebral cortical neurons in human periventricular heterotopia. Neuron 1998;21:13151325 .

2. Sheen VL, Jansen A, Chen MH, Parrini E, Morgan T, Ravenscroft R, Ganesh V, Underwood T, Wiley J, Leventer R, Vaid RR, Ruiz DE, Hutchins GM, Menasha J, Willner J, Geng Y, Gripp KW, Nicholson L, Berry-Kravis E, Bodell A, Apse K, Hill RS, Dubeau F, Andermann F, Barkovich J, Andermann E, Shugart YY, Thomas P, Viri M, Veggiotti P, Robertson S, Guerrini R, Walsh CA. Filamin A mutations cause periventricular heterotopia with Ehlers-Danlos syndrome. Neurology 2005;64:254-262.

3. Sheen VL, Dixon PH, Fox JW, Hong SE, Kinton L, Sisodiya SM, Duncan JS, Dubeau F, Scheffer IE, Schachter SC, Wilner A, Henchy R, Crino P, Kamuro K, DiMario F, Berg M, Kuzniecky R, Cole AJ, Bromfield E, Biber M, Schomer D, Wheless J, Silver K, Mochida GH, Berkovic SF, Andermann F, Andermann E, Dobyns WB, Wood NW, Walsh CA. Mutations in the X-linked filamin 1 gene cause periventricular nodular heterotopia in males as well as in females. Hum Mol Genet 2001;10:1775-1783.

4. Sheen VL, Ganesh VS, Topcu M, Sebire G, Bodell A, Hill RS, Grant PE, Shugart YY, Imitola J, Khoury SJ, Guerrini R, Walsh CA. Mutations in ARFGEF2 implicate vesicle trafficking in neural progenitor proliferation and migration in the human cerebral cortex. Nat Genet 2004;36:69-76.

5. Stossel TP, Condeelis J, Cooley L, Hartwig JH, Noegel A, Schleicher M, Shapiro SS. Filamins as integrators of cell mechanics and signalling. Nat Rev Mol Cell Biol 2001;2:138-145.

6. Beighton P, De Paepe A, Steinmann B, Tsipouras P, Wenstrup RJ. Ehlers-Danlos syndromes: revised nosology, Villefranche, 1997. Ehlers-Danlos National Foundation (USA) and Ehlers-Danlos Support Group (UK). Am J Med Genet 1998;77:31-37.

7. Zweers MC, Hakim AJ, Grahame R, Schalkwijk J. Joint hypermobility syndromes: the pathophysiologic role of tenascin-X gene defects. Arthritis Rheum 2004;50:27422749.

8. De Paepe A, Malfait F. Bleeding and bruising in patients with Ehlers-Danlos syndrome and other collagen vascular disorders. Br J Haematol 2004; 127:491-500.

9. Moro F, Carrozzo R, Veggiotti P, Tortorella G, Toniolo D, Volzone A, Guerrini R. Familial periventricular heterotopia: missense and distal truncating mutations of the FLN1 gene. Neurology 2002;58:916-921.

10. Guerrini R, Mei D, Sisodiya S, Sicca F, Harding B, Takahashi Y, Dorn T, Yoshida A, Campistol J, Kramer G, Moro F, Dobyns WB, Parrini E. Germline and mosaic mutations of FLN1 in men with periventricular heterotopia. Neurology 2004;63:51-56.

11. Dobyns WB, Guerrini R, Czapansky-Beilman DK, Pierpont ME, Breningstall G, Yock DH Jr, Bonanni P, Truwit CL. Bilateral periventricular nodular heterotopia with mental retardation and syndactyly in boys: a new X-linked mental retardation syndrome. Neurology 1997;49:1042-1047. 
12. Guerrini R, Dobyns WB. Bilateral periventricular nodular heterotopia with mental retardation and frontonasal malformation. Neurology 1998;51:499-503.

13. Robertson SP, Twigg SR, Sutherland-Smith AJ, Biancalana V, Gorlin RJ, Horn D, Kenwrick SJ, Kim CA, Morava E, NewburyEcob R, Orstavik KH, Quarrell OW, Schwartz CE, Shears DJ, Suri M, Kendrick-Jones J, Wilkie AO; OPD-spectrum Disorders Clinical Collaborative Group. Localized mutations in the gene encoding the cytoskeletal protein filamin A cause diverse malformations in humans. Nat Genet 2003;33:487-491.

14. Guerrini R. Genetic malformations of the cerebral cortex and epilepsy. Epilepsia 2005;46(suppl 1):32-37.

15. d'Orsi G, Tinuper P, Bisulli F, Zaniboni A, Bernardi B, Rubboli G, Riva R, Michelucci R, Volpi L, Tassinari CA, Baruzzi A. Clinical features and long term outcome of epilepsy in periventricular nodular heterotopia. Simple compared with plus forms. J Neurol Neurosurg Psychiatry 2004;75:873-878.

16. Chang BS, Ly J, Appignani B, Bodell A, Apse KA, Ravenscroft RS, Sheen VL, Doherty MJ, Hackney DB, O'Connor M, Galaburda AM, Walsh CA. Reading impairment in the neuronal migration disorder of periventricular nodular heterotopia. Neurology 2005;64:799-803.

17. Schalkwijk J, Zweers MC, Steijlen PM, Dean WB, Taylor G, van Vlijmen IM, Haren B, Miller WL, Bristow J. A recessive form of the Ehlers-Danlos syndrome caused by tenascin-X deficiency. N Engl J Med 2001;345:1167-1175.

18. Sharma CP, Ezzell RM, Arnaout MA. Direct interaction of filamin (ABP-280) with the beta 2-integrin subunit CD18. J Immunol 1995;154:3461-3470.

19. Calderwood DA, Huttenlocher A, Kiosses WB, Rose DM, Woodside DG, Schwartz MA, Ginsberg MH. Increased filamin binding to beta-integrin cytoplasmic domains inhibits cell migration. Nat Cell Biol 2001;3:1060-1068.

20. Cranmer SL, Ulsemer P, Cooke BM, Salem HH, de la Salle C, Lanza F, Jackson SP. Glycoprotein (GP) Ib-IX-transfected cells roll on a von Willebrand factor matrix under flow. Importance of the GPib/actin-binding protein (ABP-280) interaction in maintaining adhesion under high shear. J Biol Chem 1999;274:6097-6106.

21. Krakow D, Robertson SP, King LM, Morgan T, Sebald ET, Bertolotto C, Wachsmann-Hogiu S, Acuna D, Shapiro SS, Takafuta T, Aftimos S, Kim CA, Firth H, Steiner CE, Cormier-Daire V, Superti-Furga A, Bonafe L, Graham JM Jr, Grix A, Bacino CA, Allanson J, Bialer MG, Lachman RS, Rimoin DL, Cohn DH. Mutations in the gene encoding filamin B disrupt vertebral segmentation, joint formation and skeletogenesis. Nat Genet 2004;36:405-410.

22. Vorgerd M, van der Ven PF, Bruchertseifer V, Lowe T, Kley RA, Schroder R, Lochmuller H, Himmel M, Koehler K, Furst DO, Huebner A. A mutation in the dimerization domain of filamin c causes a novel type of autosomal dominant myofibrillar myopathy. Am J Hum Genet 2005;77:297-304.

23. Poussaint TY, Fox JW, Dobyns WB, Radtke R, Scheffer IE, Berkovic SF, Barnes PD, Huttenlocher PR, Walsh CA. Periventricular nodular heterotopia in patients with filamin-1 gene mutations: neuroimaging findings. Pediatr Radiol 2000;30:748-755.

24. Bargallo N, Puerto B, De Juan C, Martinez-Crespo JM, Lourdes Olondo M. Hereditary subependymal heterotopia associated with mega cisterna magna: antenatal diagnosis with magnetic resonance imaging. Ultrasound Obstet Gynecol 2002;20:86-89.

25. Morioka T, Nishio S, Sasaki M, Yoshida T, Kuwabara Y, Ohta M, Fukui M. Functional imaging in periventricular nodular heterotopia with the use of FDG-PET and HMPAO-SPECT. Neurosurg Rev 1999;22:41-44.
26. Aghakhani Y, Kinay D, Gotman J, Soualmi L, Andermann F, Olivier A, Dubeau F. The role of periventricular nodular heterotopia in epileptogenesis. Brain 2005;128(Pt 3):641-651.

27. Tassi L, Colombo N, Cossu M, Mai R, Francione S, Lo Russo G, Galli C, Bramerio M, Battaglia G, Garbelli R, Meroni A, Spreafico R. Electroclinical, MRI and neuropathological study of 10 patients with nodular heterotopia, with surgical outcomes. Brain 2005;128(Pt 2):321-337.

\section{Author Affiliations}

Volney L. Sheen, $M D, P h D$

Department of Neurology

Beth Israel Deaconess Medical Center

Boston, Massachusetts

Christopher A. Walsh, MD, PhD

Division of Neurogenetics and

Howard Hughes Medical Institute

Department of Neurology

Beth Israel Deaconess Medical Center

Boston, Massachusetts 